\title{
GENETIC ALGORITHM VS. REINFORCEMENT LEARNING
}

\author{
OLAH, B.
}

Abstract: The flow-shop scheduling problem is a very important practical problem. The main goal of this scientific work is to take a survey of the solution methods of permutation flow-shop scheduling problem, to demonstrate a simple evaluating algorithm, to describe a genetic algorithm approach which produces reasonably good results very quickly, finally to compare the genetic algorithm with heuristic methods (for example: priority rules in Palmer, Dannenbring's method, CDS algorithm and reinforcement learning) considering logistic conditions and objective functions such as minimum makespan, maximum machines utilization and minimum work in process inventories.

Key words: scheduling problem, genetic algorithm, reinforcement learning, makespan, idle and waiting times
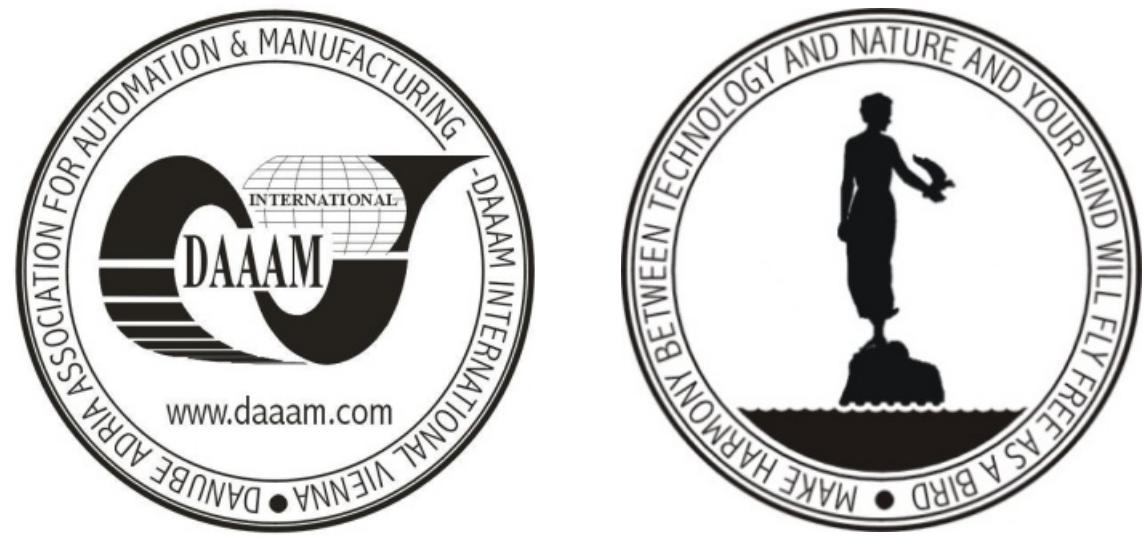

Authors' data: Dipl.-Ing. Olah, B[ela], Szolnok College Technical and Agricultural Faculty, Petofi ter 1, 5400, Mezotur, Hungary, olahb@mfk.hu

This Publication has to be referred as: Olah, B[ela] (2009). Genetic Algorithm vs. Reinforcement Learning, Chapter 80 in DAAAM International Scientific Book 2009, pp. 831-844, B. Katalinic (Ed.), Published by DAAAM International, ISBN 978-3901509-69-8, ISSN 1726-9687, Vienna, Austria

DOI: $10.2507 /$ daaam.scibook.2009.80 